\title{
DISCURSOS SOBRE IDENTIDADES NEGRAS NA CULTURA HIP-HOP
}

\author{
Ana Lúcia Silva Souza
}

\begin{abstract}
O povo negro seu nome escrito na história deixou, como um astro rei que não se apaga e brilha para todos verem que temos nosso orgulho nossa virtude e nosso valor.

Meus ancestrais lutaram e morreram pela liberdade e hoje através do rap eu faço a minha parte.

O negro tem a sua história

O negro tem o seu valor
\end{abstract}

RESUMO: Este artigo objetiva analisar de que maneira os discursos da cultura hip-hop, em especial os modos de dizer que marcam a poesia do rap, contribuem para se repensar as relações étnico-raciais no Brasil, temática especialmente importante para o momento em a Lei 10639/03, que alterou a LDB 9394/86 e tornou obrigatório o ensino da história e cultura africana e afrobrasileiras nos currículos escolares de todas as redes de ensino do país completa dez anos e ainda mostra-se como um grande desafio no que se refere à sua implementação. Com este propósito, o artigo toma como referência a letra de um rap que focaliza aspectos da história e da cultura da população negra no Brasil e organiza um discurso contundente sobre o que pode ser entendido como culturas e identidades negra.

PALAVRAS-CHAVE: Linguagem. Hip-hop. Relações étnico-raciais.

ABSTRACT: This article aims to analyze how the discourses of hip-hop culture, especially the ways to tell that marks the poetry of rap, contributes to rethink the ethnical racial relations in Brazil, furthermore important issue at the moment of the Law 10639 / 03, which modified the LDB 9394/86 and made compulsory the teaching of African and African - Brazilian culture and history at the school curriculum of all educational systems in the country, completing ten years and still viewed as a big challenge regarding its implementation. For this purpose, the article makes reference to a rap lyric that focus on aspects of the history and culture of black people in Brazil and organizes an incisive speech about what can be understood as black cultures and identities.

KEYWORDS: Language. Hip-hop. Ethnical racial relations.

Na epígrafe, o refrão do rap ${ }^{1}$ cujo título é Negro por Excelência afirma: “ $O$ negro tem a sua história; O negro tem o seu valor". Lê-se na parte inicial do rap: “ $O$

\footnotetext{
${ }^{1}$ Rap palavra de origem americana, iniciais de rhythm and poetry (ritmo e poesia). Ver referência sobre os autores da letra de rap citada em: DIMENOR, LGe et all. Hip hop: novos caminhos para educar. Jornal Bolando Aula de História - Apoio Didático para professores do Ensino Fundamental. São Paulo: Gruhbas - Projetos Educacionais e Culturais, p..14-15 - ano 9, no 68, março de 2005 - site - www.grubaspe.com.br
} 
povo negro seu nome escrito na história deixou, como um astro rei que não se apaga e brilha para todos verem que temos nosso orgulho nossa virtude e nosso valor Meus ancestrais lutaram e morreram pela liberdade e hoje através do rap eu faço a minha parte." Diante disso, afirmo eu, a letra de rap, compreendida como poesia, constitui-se em importante linguagem e, portanto, textos que devem figurar em programas e cursos de formação, inicial ou continuada, de profissionais da educação voltados à implementação da Lei 10.639/03. Lei promulgada em 2003, que altera a Lei de Diretrizes e Bases da Educação Nacional (LDB), ela inclui no currículo oficial dos estabelecimentos de ensino básico das redes pública e privada do país a obrigatoriedade de estudo da temática História e Cultura Afro-brasileira. ${ }^{2}$

Afirma-se: o rap fala, fala bem, e suas palavras e seus modos de dizer podem fazer sentidos junto a instituições de ensino nesse momento em que a Lei 10.639/03 que torna obrigatório o ensino de história e cultura africana e afro-brasileira está em fase de implementação nas escolas brasileiras. A Lei 10639/03 bem como as Diretrizes Curriculares Nacionais para a Educação das Relações Étnico-Raciais e para o Ensino de História e Cultura Afro-Brasileira e Africana -ERER, ${ }^{3}$ aprovadas posteriormente em março de 2004 são recentes e importantes medidas de ação afirmativa em favor da população negra. De modo geral, respondem a reivindicações históricas de pessoas e grupos dos movimentos sociais negros, diante da necessidade da efetivação de políticas públicas capazes de transformar a realidade brasileira que, sistematicamente, ainda exclui, ainda que sem explicitar, a história e a cultura negra do espaço escolar e, por conseguinte, os sujeitos que fazem parte do segmento negro da população.

Para assumir tal compromisso um dos primeiros passos é desfazer equívocos que, no espaço escolar se materializam, entre outras, na preocupação, em "designar ou não seus alunos negros como negros ou como pretos, sem ofensas." É nesse sentido que uma das orientações presentes nas DCN ERER assinala que:

\footnotetext{
${ }^{2}$ O sancionamento da Lei 10639/03 ocorreu após a assinatura do Plano de Ação Contra o Racismo, a Discriminação Racial, a Xenofobia e Intolerâncias Correlatas - Durban em 2001, quando o Brasil reconhecendo a existência do racismo e suas consequências e comprometendo-se a adotar políticas de ações afirmativas, um conjunto de ações concretas contra o racismo, preconceito e discriminações raciais na sociedade de forma geral e especialmente na educação.

${ }^{3}$ Doravante ao mencionarei apenas DCN ERER ao me referir às Diretrizes Nacionais para a Educação das Relações Étnico-Raciais e para o Ensino de História e Cultura Afro-Brasileira e Africana.
} 
"Em primeiro lugar, é importante esclarecer que ser negro no Brasil não se limita às características físicas. Trata-se, também, de uma escolha política. Por isso, o é quem assim se define. Em segundo lugar, cabe lembrar que preto é um dos quesitos utilizados pelo IBGE para classificar, ao lado dos outros - branco, pardo, indígena - a cor da população brasileira. Pesquisadores de diferentes áreas, inclusive da educação, para fins de seus estudos, agregam dados relativos a pretos e pardos sob a categoria negros, já que ambos reúnem, conforme alerta o Movimento Negro ${ }^{4}$, aqueles que reconhecem sua ascendência africana. (DCN ERER, 2005).

Ainda que não exclusivamente, é da escola a empreitada maior de acolher, conhecer e valorizar outros vínculos históricos e culturais, refazendo repertórios cristalizados em seus currículos e projetos pedagógicos e nas relações estabelecidas no ambiente escolar, promovendo uma educação de qualidade para todas as pessoas. Como aparece nas DCN ERER, o enredamento da tarefa requer aprendizagens que "questionem relações étnico-raciais baseadas em preconceitos que desqualificam os negros e salientam estereótipos depreciativos, palavras, atitudes que, velada ou explicitamente violentas, expressam sentimentos de superioridade em relação aos negros, próprios de uma sociedade hierárquica e desigual” (DCN ERER: 2005:12).

Se a escola aparece como lócus privilegiado para agenciar as alterações há que se pensar nos usos sociais da linguagem na escola adotando a concepção que entende letramentos como "um conjunto de práticas sociais, cujos modos específicos de funcionamento têm implicações importantes para as formas pelas quais os sujeitos envolvidos nessas práticas constroem relações de identidade e de poder" (KLEIMAN, 1995, p. 11). A visão de que os letramentos, na escola e fora dela são múltiplos e heterogêneos e que as práticas de uso da linguagem são modeladas e construídas culturalmente, e estão relacionadas aos papéis e aos lugares sociais que ocupamos na sociedade é fundamental quando as políticas públicas afirmam que ainda temos de criar "pedagogias de combate ao racismo e a discriminações". Para além dos dispositivos legais trata-se de inserir-se em um processo de reeducação: conhecer, entender,

\footnotetext{
4 "o Movimento Negro ressignificou esse termo dando-lhe um sentido político e positivo. Lembremos os motes muito utilizados no final dos anos 1970 e no decorrer dos anos 1980, 1990: Negro é lindo! Negra, cor da raça brasileira! Negro que te quero negro! 100\% Negro! Não deixe sua cor passar em branco! Este último utilizado na campanha do censo de 1990". (DCN ERER: 2005)
} 
esmiuçar, rever, reconstruir as idéias e noções e práticas que até então amparam as desigualdades étnico-raciais que em todos os níveis de ensino se fazem presente. ${ }^{5}$

Considerando-se nossa sociedade multirracial e multiétnica, profundamente marcada por desigualdades e contradições, ditas e não ditas, vivemos um momento privilegiado em que práticas isoladas voltadas para educação antirracista podem dar lugar a um olhar crítico, a um diálogo denso e tenso do qual não se pode mais fugir.

Assumir a tarefa requer entender, como quer Hall (2003), o terreno da cultura como um espaço de batalha por significações, que se torna ainda mais tenso e disputado quando as rápidas transformações por que passam as sociedades enfraquecem as narrativas locais, o que provoca o deslocamento de antigas hierarquias. Nesses contextos, são engendradas práticas sociais diversificadas que obrigam a conceber o surgimento de novas formas de perceber e validar as práticas populares, as práticas cotidianas. O autor afirma que a análise dos novos contornos que a cultura adquire requer compreendê-la como uma luta cultural, como um campo de ações, atos e situações que, no processo histórico, assume diversas formas.

É na dinâmica social, aponta o autor, que os elementos de distintas tradições se encontram e "podem ser reorganizados para se articular a diferentes práticas $e$ posições e adquirir um novo significado e relevância" (HALL, 2003, p. 260). Os novos significados são parte de um processo de mudança pelo qual passam as diferentes culturas, também a cultura negra. Nesse sentido, a cultura negra não tem sido mais compreendida como imutável, dotada de essencialidade, mas sim como um sistema de significações em permanente mudança.

O terreno da cultura e da tradição compreendido como pleno de cruzamentos de ideias e interesses distintos e os conflitos e as tensões oriundos do embate de forças

\footnotetext{
${ }^{5}$ Levando em consideração um recorte com foco na população acima dos 15 anos, segundo dados do censo escolar de 2007 entre os jovens brancos, 70\% haviam concluído o ensino fundamental, enquanto que dos negros, apenas 30\%. No ensino médio, $62 \%$ de jovens brancos, 15 a 17 anos, estavam na escola enquanto havia $31 \%$ de jovens negros. Considerando-se o recorte etário aos 19 anos, $55 \%$ de brancos concluem o ensino médio enquanto apenas $33 \%$ de negros conseguem concluir. Além disso, da população branca acima de 25 anos, $12,6 \%$ detém diploma de curso de nível superior enquanto dentre os negros a taxa é de 3,9\%. ${ }^{5}$ Os dados do Instituto de Pesquisa Econômica Aplicada - IPEA, de 2008, ${ }^{5}$ evidenciam a falta de equidade, o que significa não apenas garantir acesso universal, mas principalmente a permanência sustentada pela existência de um ambiente e de um projeto político em que a diferença seja ponto de partida para compreender as diversidades em busca da igualdade no que se refere ao usufruto dos direitos socialmente construídos. Desigualdades raciais, racismo e políticas públicas: 120 anos após a abolição. Brasília: Instituto de Pesquisa Econômica Aplicada, 2008. Disponível em: www.ipea.gov.br/sites/000/2/pdf/08 0513120 anos Abolicão V coletiva.pdf
} 
podem ser entendidos como matérias primas para as apropriações e negociações nas quais os setores dos grupos socialmente minorizados se engajam. São apropriações e negociações que interferem e sustentam a construção das identidades sociais.

A noção de cultura, longe de comportar o anacronismo e a "pureza", é o local no qual são operadas transformações em decorrência dos embates de dominação e de resistências constitutivos das relações políticas e sociais ao longo dos tempos. Dessa maneira, a cultura não se encerra como um estrato autêntico e imutável, tampouco como absolutamente encapsulada pelas formas da dominante de cultura. Como observa Hall (2003), a cultura se configura

\begin{abstract}
"nas linhas complexas da resistência e da aceitação, da recusa e da capitulação, que transformam o campo da cultura em uma espécie de campo de batalha permanente, onde não se obtém vitória definitiva, mas onde há sempre posições estratégicas a serem conquistadas ou perdidas." (p. 255).
\end{abstract}

Talvez o medo de enfrentar as tensões provoque a dúvida: dizer ou não dizer de cultura negra. O silenciamento em torno da questão racial impede discussões e reflexões que possam explicitar que o termo raça não é pensado como categoria biológica, mas como uma construção política e social e, como afirma Hall (2003, p. 69), é em torno dessa categoria discursiva que "se organiza um sistema de poder socioeconômico, de exploração e exclusão - ou seja, o racismo." Concepção que justifica as diferenças sociais e culturais como dados biológicos naturalizando-as.

Podemos entender, para usar uma expressão de Paixão (2008) que “a pobreza no Brasil tem cor: negra (p.13) ${ }^{6}$. No relatório sobre desigualdades raciais no Brasil o economista amplia as possibilidades de compreensão da categoria pobreza para além do acesso a bens materiais, de modo que também deva ser lida pelo ângulo da posse de ativos imateriais, tais como os educacionais, de proteção à vida, ${ }^{7}$ bem como da validade

\footnotetext{
${ }^{6}$ Argumento defendido por setores dos movimentos sociais negros: as desigualdades raciais, como parte da realidade, não pode ser vista isoladamente em relação às desigualdades sociais, tampouco outros marcadores tais como de gênero e sexualidade, por exemplo.

${ }^{7}$ As vítimas da violência têm idade, classe social e cor é título de matéria publicada na Revista Mundo Jovem divulga dados do Mapa da Violência dos Municípios Brasileiros de 2008. Os dados mostram que, entre 1996 e 2006, os índices de homicídios da população jovem teve um aumento de $31,3 \%$, enquanto na população total a porcentagem fica em $20 \%$. Ao mergulhar nos dados referentes à mortalidade juvenil afirma que "A pobreza tem cor, e no Brasil ela é negra. Os negros apresentam um índice de vitimização $73,1 \%$ superior aos brancos na população total e $85,3 \%$ superior na juventude," (p. 11). Por fim, ao denunciar o extermínio
} 
de reivindicações coletivas no plano político”. Paixão (2008) assevera que, mesmo reconhecendo que existam pessoas pobres de diferentes cores ou raças, ou ainda negros e negras com maior renda, os motivos da existência da pobreza não são os mesmos para os diferentes grupos. Para o segmento negro a principal causa da pobreza é a persistência do racismo, do preconceito, e também da discriminação racial, que não isenta as pessoas negras de maior poder aquisitivo ou nível mais elevado de escolarização e acesso a esferas de prestígio como a universidade.

Podem-se detectar movimentos de configuração na e pela cultura negra, que se dão entre batalhas por sentidos, presente no hip-hop quando focalizamos os discursos de ativistas que "sem medo de ser negro" contribuem para nos enredar discursivamente em uma teia de significados que instigam a interrogações, indagações, mas não silenciamentos. A contribuição é profícua nesse início de século XXI - ainda há medo de usar o termo negro para referir-se a pessoas de ascendência africana.

\section{HIP-HOP E CULTURA NEGRA}

O movimento hip-hop, expressão que significa "saltar movimentando os quadris” ${ }^{8}$, tem sido apontado como importante fenômeno urbano juvenil no cenário sócio-político do país. Protagonizado por jovens, em sua maioria negros e negras, de baixo poder aquisitivo, que moram nas periferias das capitais brasileiras, chama a atenção, entre outros aspectos, por mostrar significativo potencial de gerar identificação e articulação em torno da cultura negra. (ANDRADE, 1996).

No Brasil desde meados de 1980, o hip-hop, que se desenvolve com mais força nos grandes centros urbanos, espalha-se por todo o país e, estrategicamente, afirma um discurso de denúncia e proposições por meio de expressões materializadas em quatro elementos: a dança de movimentos quebrados; o grafite da arte em desenhos coloridos com técnicas e suportes diversos; a palavra cantada do MC, o mestre de cerimônias que

também apostam na organização coletiva, também da juventude, na ocupação dos espaços públicos e na reivindicação dos direitos como possibilidade de reverter a lógica perversa dos números. "(www.mundojovem.com.br) Mundo Jovem de fevereiro de 2009.

\footnotetext{
${ }^{8}$ No dicionário Houaiss, lê-se que o hip-hop é "um movimento cultural da juventude pobre de algumas das grandes cidades norte-americanas que se manifesta de formas artísticas variadas".
} 
leva as mensagens ao público e o DJ que cuida da manipulação de aparelhagens eletrônicas.

Adentrar o universo dessas produções culturais mostra um incessante processo de criação em que jovens mulheres e homens se juntam em grupos de estudo, se encontram para discutir sobre a dinâmica e as transformações do hip-hop, organizar eventos e shows, pensar em questões emergentes e importantes em suas vidas. Em meio a esse processo, eles criam diversas e variadas oportunidades de contato e manejo da língua escrita, oral e imagética; práticas sociais que, partindo dos conhecimentos que possuem, os inserem em um processo coletivo de investigação que promove aprendizagens, amplia as habilidades e conhecimentos que atendem às necessidades criadas nos fazeres de rappers. ${ }^{9}$

Nos grupos, os jovens desempenham um papel educativo que, em grande medida, responde às demandas sociais em torno da leitura, escrita e oralidade, adensando não apenas o próprio processo de inserção no mundo letrado, mas também dos que estão em sua volta. Mais que saber ler, escrever e falar interessa saber como e por que as pessoas o fazem, com que sentidos e como estes usos das linguagens interferem em suas maneiras de lidar com as situações em que estão envolvidas no cotidiano.

Dessa forma o hip-hop mostra-se como espaço cultural e político de desenvolvimento de práticas socioeducativas e de autoafirmação da cultura negra e, de maneira singular, reinventam histórias também de outras produções: maracatu, jongo, maculelê, congadas, samba, a depender dos lugares onde se desenvolve. Em Minas Gerais, por exemplo, é comum assistir apresentações ou participar de debates em que os mais jovens dividem microfone com os velhos e velhas das congadas, com os praticantes de capoeira.

O rap é a face mais visível do hip-hop, resultante da junção das técnicas de DJs e MCs. Pode-se dizer que, no rap, o DJ é parte do ritmo, do balanço, do swing da música e o MC é a parte da poesia, da letra, da linguagem escrita e da oralidade. Geralmente gestos, falas, leituras, escritas e imagens, em vários contextos, descortinam formas de produzir conhecimentos sobre história, a cultura, sobre o cotidiano das periferias. Ainda que o movimento hip-hop não seja homogêneo, de um modo geral, há uma

\footnotetext{
${ }^{9}$ Rapper ou hip hopper designam as pessoas que mantém relações com o universo do hip
} hop, por meio de qualquer uma de suas expressões Lindolfo Filho ( 2005) e Jovino (2005). 
preocupação em qualificar o trabalho, em especial a elaboração das letras de rap que revelam, nas linhas e entrelinhas, os conflitos vividos pela população excluída.

\section{SENTIDOS DOS DISCURSOS NO RAP}

A poesia do rap pode nos ajudar a dar os primeiros passos para entender a complexidade das relações raciais no Brasil, o que exige problematizar e esmiuçar como são, histórica e socialmente, construídas as concepções racistas e como em torno delas são engendrados os esquemas interpretativos que informam e orientam as práticas preconceituosas e discriminatórias, muitas vezes "silenciosas", silenciadas e naturalizadas, a tal ponto que a palavra negro em sentido positivo e empoderador quase é banida do dicionário do cotidiano do espaço escolar.

Para um posicionamento contrário ao silenciamento inicialmente pensemos no termo negro, como faz Hall (2003) considerando-o "negro" dentro de um campo semântico ou uma formação ideológica particular, em vez de um termo isolado: dentro de sua cadeia de conotações. (p. 192) onde o autor r trabalha com dois exemplos. Um deles está na cadeia na qual o corpo negro - negro-preguiçoso-invejoso-traiçoeiromalevolente-feio-de-cabelo-ruim - flui da identificação de "negros" dentro de um momento histórico específico que no Brasil está na época da escravização comercial de pessoas trazidas de países do continente africano. Em relação a isso Hall (2003) nos alerta para o fato de que, "embora a distinção "negro/branco" articulada por essa cadeia não seja dada simplesmente pela característica daquele momento histórico específico constituem seu referente nesta formação discursiva específica” (p. 69), pois para ele "negros" e suas conotações são uma forma de representar como as pessoas de caráter étnico distinto foram inseridas nas relações sociais de produção. Ficam elas marcadas como coisas, mercadorias.

Junto a essa cadeia de conotações há outra, diferente gerada nos estudos filosóficos e dentro de discursos religiosos "a associação da luz com Deus e o espírito, a da Escuridão ou "negrume" como o Inferno, o Diabo, o pecado e a condenação" (HALL, 2003, p 192). Como se presencia no ambiente escolar, mas não só nele, tudo o que é negro é ruim, gato preto dá azar, a coisa está preta quando algo não vai bem. 
Agora ao ler o discurso no rap em foco, aos poucos, vejamos de que maneira os sentidos construídos se afastam das duas cadeias anteriores e constroem uma terceira cadeia de significados.

\author{
De repente alguém deu a sugestão pegaram um toca disco \\ e samplearam um batidão com o pai do hip-hop muita força \\ de expressão, África Baambata, uma forma de protesto contra a \\ discriminação \\ o negro chegou ao Brasil, antes colônia de Portugal. \\ Trouxe sua cultura descobriu o berimbau, surgiu a capoeira \\ cem por cento nacional \\ Não esqueceu sua cultura seu batuque original, mesmo \\ escravizado o negro se virou e na cultura popular o negro \\ ajudou, inventou a feijoada com o que sobrou \\ Hoje prato popular que a muitos agradou. \\ O negro tem a sua história \\ O negro tem o seu valor
}

Somente focando o refrão $O$ negro tem a sua história $O$ negro tem o seu valor pode-se perceber que já ganha corpo outra história de construção de sentidos em torno da categoria negro. Podemos pensar com Hall (2003) que é a busca de construção de um espaço em que se quer reconhecer positivamente a experiência negra, criando uma unidade capaz de fazer surgir um sujeito coletivo que possa ser chamado de "massas negras em luta”. Esse é um dos papéis que o hip-hop chama para si, quando, logo no início faz referência a ações de combate ao racismo e se perfila a outros movimentos sociais negros que, historicamente, têm empreendido esforços para desnaturalizar o conceito de negro, trazendo aspectos que podem contribuir para elevar a auto-estima das pessoas e alterações visões ainda cristalizadas e naturalizadas.

E o rap segue com uma história ainda pouco contada no âmbito escolar:

Na Bahia a batucada se manifestou, influência para o samba Que o negro criou, na Jamaica um novo estilo se criou, nascia o reggae que anos depois Bob espalhou, o reggae roots que me encantou.

Nem toda escrita tem o seu valor, são milhões de histórias que o branco não contou.

Negro por excelência Deus me proclamou, só que dessa parte o branco não lembrou.

O negro tem a sua história

O negro tem o seu valor

A letra mostra a coragem de enfrentar o que nas DCN ERER é apontado ainda 
como um equívoco fundamental para a construção de pedagogias de combate ao racismo e a discriminações que estão por criar que é o medo e a "preocupação de professores no sentido de designar ou não seus alunos negros como negros ou como pretos, sem ofensas". (2004, p. 9). O medo enfrentado também por pessoas de ascendência africana que também por vezes buscam negar aspectos que os identifiquem como pertencentes ao segmento.

Ainda que se possa estender a análise, por ora vale destacar a potencialidade do rap para problematizar a ideia de um Brasil da democracia racial, sem o que dificilmente poderão ser situadas as "descordialidades" tampouco compreender como a democracia racial se faz mito, escamoteando os conflitos e contradições que, em nome da pretensa igualdade, acabam por reproduzir e amparar doutrinas, opiniões e atos racistas.

O rap se posiciona contrariamente a ações que escondem e negam as diferenças e dão visibilidade apenas aos valores de alguns grupos que chancelados em detrimentos de outros, de forma que a polarização superior-inferior engendra uma segregação eficiente, na medida em que é dissimulada. Como explicar que os grupos herdam e recriam legados singulares e que suas diferenças culturais não se associam às relações de poder que se traduzem em hierarquizações de toda sorte? Como explicar que assumir como princípio básico as diferenças é pressuposto para discutir e negociar, entre os diferentes, projetos capazes de promover relações de igualdade frente aos direitos constitucionais conquistados?

Outro aspecto relacionado ao anterior aponta a necessidade de se reconhecer que no Brasil, o racismo, bem como o preconceito e a discriminação racial, são elementos estruturantes da sociedade e ainda balizam as relações sociais e institucionais, hierarquizando as diferenças e inferiorizando um grupo, o negro, em detrimento de outro, o branco. Como decifrar os tantos indicadores de pesquisas e estudos que desagregados por cor/raça invariavelmente demonstram desigualdades expressivas entre brancos e negros?

Do reconhecimento e afirmação das diferenças à construção de igualdades de direitos temos ainda um longo percurso e grandes desafios, para os quais toda a sociedade está convocada a assumir. Como o faz o rap dizendo cumprir a sua parte:

sou tipo o soldado do Afeganistão 


\author{
o homem bomba da favela, o vulcão em erupção \\ o super homem que incentiva a viagem do pivete \\ sou Mandela, sou Zumbi, Lampião lá no nordeste \\ eu sou a fúria, Antonio Conselheiro, sou Lamarca, Luis Gama \\ sou Zapata, sou guerreiro \\ sou viagem sociedade, sou rapper nacional \\ Dimenor do Parque Bristol pra burguês não pagar pau \\ O negro tem a sua história \\ $O$ negro tem o seu valor
}

No trecho está presente a afirmação de identidade negra, pela cultura e história brasileira, além de trazer importantes aspectos históricos sobre as pessoas e movimentos sociais de outros lugares. Nele percebe-se a aproximação com fontes e referências diversas, o que mobiliza conhecimentos prévios, pesquisa em fontes escritas ou orais. É dessa forma que os jovens enfrentam o silêncio que muitas vezes conhecem na escola: aproximam-se de leituras e escutas de temas e autores com objetivos definidos: conhecer a história e a cultura para dar suporte às argumentações.

No hip-hop os valores atribuídos à linguagem junta à tradição de ancestralidade a oralidade e, mais recentemente, com o avanço das novas tecnologias de informação, inventa maneiras nas combinações e recombinações nos quatro elementos. As marcas do hibridismo ${ }^{10}$ (CLANCINI, 2005) são percebidas na hora de cantar, e usar partes de outras músicas, nos modos como os/as MCs usam publicamente a fala, com desenvoltura, estudando o tom das palavras e, também, imitando instrumentos com a boca e outros recursos que imprime ênfase às singularidades do hip-hop.

O movimento na busca por acesso aos bens culturais mostra a existência de outras formas de ler e de falar materializados nos fanzines, nos jornais e na literatura crônicas, contos e poesia que criam vida nos saraus que se alastram pelas regiões da periferia, como é o caso de São Paulo. Parte dele informa e sustenta a produção de sites e grupos de discussão na Internet, bem como de vídeos e documentários. De maneira geral ser do hip-hop envolve, em maior ou menor grau, a leitura e a escrita de imagens e circulação de diferentes materiais para estruturar o conjunto de idéias que abarca esse tipo de texto e, que ainda, pode ser feito individual ou coletivamente, aprendido e

${ }^{10}$ Empresto o conceito de hibridização de Canclini (2005) que o entende como "processos socioculturais nos quais estruturas ou práticas discretas, que existem de forma separada, se combinam para gerar novas estruturas, objetos e práticas" ( $p . X I X)$. O mesmo autor assinala que o conceito, empregado com vários significados, adquire relevância nas ciências sociais e outros campos de conhecimento que buscam apreender as complexas relações que se estabelecem em meio a configurações sócio-políticas e culturais. 
ensinado por meio das oficinas que atualmente acontecem dentro e fora das comunidades de periferia. Geralmente, as oficinas de grafite, de DJ, de dança de MC, de produção também exigem preparativos que vão desde os momentos para definir os locais, formatos, roteiros, estratégias, até a avaliação.

Além disso, concordando com Gomes, (1999) a participação em espaços e instâncias públicas conecta estes grupos a outros, seja para construir alianças, seja para apresentar demandas e propostas gerais e também específicas pertinentes à agenda mais ampla - racial, social, étnica, etária, cultural, de gênero, ambiental, o que tende a fortalecer os integrantes.

A cultura transforma-se em movimento por mostrar-se capaz de envolver diferentes pessoas e grupos numa rede de acontecimentos na qual as práticas sociais de leitura, escrita e a oralidade têm objetivos e função voltados para questões de interesse dos grupos. Em contato com os jovens, não é difícil ouvir que, para muitos, a participação no movimento imprime mudanças significativas em seu modo de agir e posicionar-se diante da produção e da circulação de conhecimento sobre o mundo. Isso, na medida em que amplia o repertório cultural e político, fortalece as idéias sobre questões sociais e raciais e sobre juventude, propõe novas maneiras de gestar, organizar e realizar as práticas que asseguram o aprender e ensinar para a vida.

Neste cenário de fala, os gestos cadenciados, as imagens e cores de suas roupas e dos ambientes reforçam a postura de enfrentamento pretendida, o que por vezes assusta quem não aposta nas possibilidades da validade de letramentos em espaços não formais de educação.

Quem são estes jovens, homens e mulheres, de roupas largas, blusas e camisetas estampadas com palavras de ordem em favor da população negra da periferia? Que falam bastante e bem, movimentam-se em grupos, carregam agendas ou cadernos rabiscados com letras e desenhos que nem todos entendem, declaram gostar de ler e escrever e quando em sala de aula puxam assuntos polêmicos? Estas indagações têm despertado o interesse das organizações não governamentais, de diversos setores do poder público, em especial da escola (JOVINO, 2005). Algumas das organizações, para responder a estas e outras questões, começam a entender que, mais que atividades pontuais em horários vagos ou esporádicos ou em alguns finais de semana, é preciso ouvir quem está dizendo e o que está dizendo e dispor-se a descobrir as múltiplas 
maneiras e lugares onde circulam conhecimentos e valores que, articulados às necessidades e interesses dos jovens possibilitam a participação e a intervenção na realidade em que se vive. São muitas e novas vozes que ecoam mostrando que os/as jovens por meio de gestos negros ampliam a capacidade de criar e fazem muito mais que balançar (hip) os quadris (hop) (SOUZA, 2005). São jovens, homens e mulheres negros e negras ou brancos e brancas que vivem a mesma realidade e que estão fazendo, arte, história e cultura.

Por fim, novamente recorro a Hall (2003) que nos ajuda a continuar indagando sobre a cultura negra quando defende que conceitos em disputa tais como o de raça, negro, cultura e outros termos a eles relacionados devem sempre ser usados "sob" rasura. Sob rasuras, mas, contudo usados (e não silenciados) pois, ainda que complexos e nem sempre fáceis de entender, são eles que na atualidade permitem continuar a interrogar sobre as batalhas de sentido que nos posicionam e reposicionam frente às questões sociais. E são as interrogações que podem servir para não nos contentarmos com explicações naturalizadas e fugir tanto dos essencialismos estigmatizantes como das relativizações ou dos disfarces que estão dentro de conceitos, também, pouco explorados como o de diversidade.

As interrogações e os diálogos são condições fundamentais para que se instaure uma política que faça do reconhecimento das diferenças caminho para revisitação de condutas e busca de referenciais para a construção de igualdades de direitos.

\section{REFERÊNCIAS}

ANDRADE, E. N. Movimento negro juvenil: um estudo de caso de jovens rappers de São Bernardo do Campo. Dissertação de Mestrado. São Paulo: USP, 1996.

BRASIL. Diretrizes Curriculares Nacionais para a Educação das Relações ÉtnicoRaciais e para o Ensino de História e Cultura Afro-Brasileira e Africana. http://portal.mec.gov.br/cne/.

BRASIL. Lei $n^{\circ}$ 10.639, de 09 de janeiro de 2003. http://www.planalto.gov.br/ccivil_03/leis/2003/L10.639.htm

CANCLINI, N. G. Culturas híbridas - estratégias para entrar e sair da modernidade. Rio de Janeiro: Editora EDUSP, 2005. 
DAYRELL, J.T A Música Entra em Cena - O rap e o funk na socialização da juventude. Belo Horizonte: Editora UFMG, 2005.

DIMENOR, LGe et all. Hip hop: novos caminhos para educar. Jornal Bolando Aula de História - Apoio Didático para professores do Ensino Fundamental. São Paulo: Gruhbas - Projetos Educacionais e Culturais, p..14-15 - ano 9, n 68, março de 2005 - site www.grubaspe.com.br

GOMES, N. L. Rappers, educação e identidade racial. In: LIMA, I. et al (orgs). Educação popular afro-brasileira. Florianópolis, Núcleo de Estudos Negros, $n^{\circ} 5$, 1999.

KLEIMAN A. B. Modelos de letramento e as práticas de alfabetização na escola In: . (Org.) Os Significados do Letramento. Campinas, S.P: Mercado de Letras, 1995.

HALL, Stuart. Da diáspora: Identidade e mediações culturais/ Stuart Hall;

Organização Liv Sovik; tradução Adelaine La Guardiã Resende... [et all.]. Belo Horizonte: Editora UFMG; Brasília: Representação da UNESCO no Brasil, 2003

JOVINO, I. As Minas e os Manos têm a Palavra. Dissertação de Mestrado - Faculdade de Educação São Carlos, UFSCar, 2005.

MUNANGA, K. GOMES, N. L. Para entender o negro no Brasil de hoje: histórias, realidades, problemas e caminhos. Ed. Global e Ação Educativa, 2004.

PAIXÃO, M. CARVANO, L. M. Relatório Anual das Desigualdades Raciais no Brasil; 2007-2008. Rio de Janeiro, Instituto de Economia da UFRJ, Editora Garamond Ltda, 2008.

SOUZA, Ana L. S. Os sentidos da prática de lazer da juventude negra. In: Racismo no Brasil: percepções da discriminação e do preconceito no século XXI.

SANTOS, G e SILVA, M.P. (org.) São Paulo: Editora Fundação Perseu Abramo, 2005.

Letramentos de reexistência: poesia, grafite, música, dança: HIP-HOP. Autor: Ana Lúcia Silva Souza. Editora Parábola, 2011.

RECEBIDO EM: 01 de novembro de 2012 APROVADO EM: 06 de dezembro de 2012 